\title{
FONOLOŠKI OPIS HRVATSKOGA DVOGLASNIKA I SLOVAČKIH DVOGLASNIKA ${ }^{1}$
}

$\mathrm{F}_{\mathrm{w}}$ onološki sustavi hrvatskoga i slovačkoga jezika obilježeni su postojanjem dvoglasnika. I dok u hrvatskom postoji jedan, k tomu još uvijek sporan dvoglasnik $/ \Delta /$, slovački samoglasnički sustav sadržava četiri dvoglasnika: /ia/, /ịe/, /ịu/, /uno/, koji se ostvaruju kao kombinacije poluvokala (kliznika) $i$, $u$ i kratkih samoglasnika. Grafemski se prikazuju pomoću $i a, i e, i u, \hat{o}$, pri čemu samo posljednji grafem jednojednoznačno upućuje na fonemsku interpretaciju, dok su prva tri rješenja homografna s bifonematskim kombinacijama $i a, i e, i u$. To je jedna od grafijskih nedorečenosti slovačkoga pravopisa, a zbog utjecaja pravopisa na izgovor, otvara i brojna ortoepska pitanja. Štoviše, mogu se naći minimalni parovi u kojima različito ostvarenje digramskih kombinacija (kao dvoglasnik ili kao bifonematska skupina) upućuje na različite lekseme:

\begin{tabular}{|c|c|c|}
\hline $\begin{array}{l}\text { hostia } \\
\text { [yost'ia }]\end{array}$ & $\sim$ & $\begin{array}{l}\text { hostia } \\
\text { [yostia] }\end{array}$ \\
\hline "gosti" & & "hostija" \\
\hline $\begin{array}{l}\text { razia } \\
{[\text { razia] }}\end{array}$ & $\sim$ & $\begin{array}{l}\text { razia } \\
\text { [razia] }\end{array}$ \\
\hline "kuju (k & ice)" & "racija" \\
\hline
\end{tabular}

Kao što se može primijetiti, svi su slovački dvoglasnici tzv. uzlazni dvoglasnici (slovački stúpavé dvojhlásky), tj. ostvaruju se postupnim otvaranjem usta, odnosno povećanjem čeljusnoga kuta (Král' - Sabol, 1989:143). Jelaska (2004:42) ih naziva pristupnim dvoglasnicima, jer slabiji član pristupa jačemu, kojemu u linearnom slijedu prethodi. Stariji fonološki opisi u dvoglasnike su redovito uvrštavali i ou [ou ], koji se pojavljuje u nastavku instrumentala jednine ženskoga roda svih deklinacija (na primjer ženou). Međutim Jakobson (1931:157sq) je nedvojbeno dokazao da se taj fonetski dvoglasnik fonološki može interpretirati kao bifonematska skupina /ov/, budući da se $v$ u odstupu sloga (eng. $\operatorname{coda}$ ) u slovačkom pravilno ostvaruje kao [u․ . Na isti se način mogu interpretirati i drugi površinski silazni dvoglasnici poput au, eu i sl., koji se pojavljuju u posuđenicama.

Bilo je pokušaja da se u samoglasnički inventar uvrsti i dvoglasnik ịo (Dvonč, 1968), za koji postoji otvoreno mjesto u sustavu, a pojavljuje se tek u posuđenici matrioška "babuška (figura)". Osim toga, io je redovit način fonološkoga prilagođavanja ruskoga $\ddot{e}$ pri transkripciji ruskih naziva i imena. I u slovačkom inherentnom rječniku mogu se naći strukturalne pretpostavke za taj dvoglasnik, na primjer od toponima Babia Hora nameće se pridjev *babiohorský, iako je standardizirano babohorský. Stoga možemo zaključiti da je

Rad je neznatno izmijenjena inačica istoimenoga rada objavljenog u časopisu Govor, XXV (2008), $45-54$. 
status toga dvoglasnika krajnje marginalan te ga Sabol (1989:111) posve opravdano naziva "diftongoidom".

Suvremena slovačka fonološka teorija danas se slaže o fonološkome karakteru dvoglasnika, međutim tijekom mnogih desetljeća to je bio predmet oštrih rasprava. Sukobljavale su se uglavnom dvije oprečne struje, odnosno teorije o fonološkom karakteru slovačkih dvoglasnika: bifonematska i monofonematska. Bifonematska je teorija starija, a glavni su joj predstavnici bili L’udovít Novák i Eugen Pauliny, iako se pojavljuje još kod začetnika strukturalističke fonologije Trubeckoga i Jakobsona. Zagovornici bifonematske teorije smatrali su da su slovački dvoglasnici sastavljeni od dvaju fonema - poluvokala (kliznika) i kratkoga samoglasnika. Za takvo stajalište uporište su nalazili u mornome shvaćanju slovačke kvantitete. Naime, ako dugi samoglasnik $\bar{a}$ vrijedi dvije more, a kratki $a$ jednu moru, dugi se samoglasnik može prikazati formulom $\bar{a}=a+a$. Tada i dvoglasnike, koji kvantitativno također vrijede dvije more, možemo prikazati sličnom formulom, $\mathrm{tj} .: \underset{\lambda}{i} a=i+a, \underset{\wedge}{i} e=$

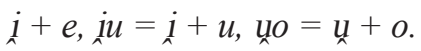

Najveća prednost mornoga poimanja kvantitete mogućnost je ekonomičnoga definiranja zakona o ritmičkom kraćenju, koji se time svodi na pravilo prema kojem se u slovačkom u dvama slogovima ne mogu naći više od tri more. To automatski povlači i bifonematsko shvaćanje dvoglasnika koji su kvantitativno dugi, te kao takvi uzrokuju djelovanje zakona o ritmičkom kraćenju, ali mu i podliježu. Drugim riječima, dvoglasnici uzrokuju kraćenje sljedećega dugog sloga, ali i sami bivaju skraćeni ako se nađu u poziciji neutralizacije: češú "češljaju”, ali viažu "vežu”, srdcia "srca (nominativ množine)", ali plúca "pluća".

Kao što se u poziciji neutralizacije dugi samoglasnik zamjenjuje kratkim time što gubi jedan kratki samoglasnik, tako i dvoglasnici, prema bifonematskoj teoriji, gube neslogotvornu sastavnicu, kliznik $\underset{\wedge}{i}$ ili $u_{x}$, te ostaje samo kratki samoglasnik - slogotvorni dio dvoglasnika (Pauliny, 1968:72), tj.

\begin{tabular}{|c|c|c|c|c|c|}
\hline \multirow{3}{*}{ mòre: } & ro-bíšs & $\sim$ & *chvá-líšs & $\rightarrow$ & chvá-liš \\
\hline & $x x$ & & $x \times$ & & $x x$ \\
\hline & srd-cia & $\sim$ & *pl'ú-cia & $\rightarrow$ & pl'ú-ca \\
\hline
\end{tabular}

No, u takvoj je argumentaciji skrivena kružna definicija. Naime, pokazuje se da su upravo dvoglasnici i njihovo sudjelovanje u ritmičkome zakonu glavni argument za morno poimanje slovačke kvantitete (budući da kraćenja tipa $\bar{a} \rightarrow a$ možemo objasniti jednostavnije), a istodobno se iz takvoga poimanja izvodi bifonematičnost dvoglasnikā. To je primijetio Horecký (1974:51) u argumentacijskome slijedu Trubeckog (Trubeckoj, 1960:211sq) i Paulinyja (Pauliny, 1968:68).

Bifonematski pristup više stvara teškoće u opisu nego što donosi koristi. Prije svega, uvodi dva nova fonema u slovački fonološki sustav ( $i$ i u dvoglasnika, ali ta se dva glasa inače ostvaruju kao alofoni fonema $j$ i $v$, pri čemu $u$ ima neke naznake fonemičnosti, dok je distribucija i potpuno predvidljiva. Kliznike $i$, u u tome slučaju ne bi bilo moguće fonološki identificirati na dubinskoj razini, jer bi jedanput bili fonemi, a jedanput alofoni, pri čemu se distribucija ne bi mogla odrediti položajem u slogu. Král' (1988:107) na primjer spominje da se zjest' "pojesti” može ostvariti kao [zjest'] i kao 
[ziest'], a $j$ se nalazi u istom položaju u slogu kao u viem [viem] “"znam”, gdje se radi o izvornom dvoglasniku. Da se $u$ prizna kao samostalni fonem, postojala bi fonološka opozicija $v$ $\sim$ u, na primjer u minimalnim parovima voz "kola" ôs "ôsā", fonološki vos unos (Horecký, 1974:50) ili stôl "stol" stvol "stabljika", fonološki stuol stvol (Sabol, 1989: 113), koji prema 2. pravilu Trubeckoga o razlikovanju fonema i alofona (Trubeckoj, 1960: 55) signaliziraju različite foneme. S druge strane, riječ slovník "rječnik" može se ostvariti kao [slovńīk] i kao [slouńnîk], što prema 1. pravilu Trubeckoga (Trubeckoj, 1960: 53) upućuje na varijante istoga fonema. Dakle, izvan korpusa riječi s dvoglasnicima ne nalazimo primjere koji bi zadovoljavali komutacijske testove za dokazivanje potencijalnih fonema $i$ i u. Zanimljivo je da je na gotovo identičan problem naišao i Brozović (1991: 452) pri dokazivanju fonemičnosti prvoga dijela hrvatskoga dvoglasnika.

Nadalje, nastala bi neravnoteža u morfonološkom sustavu, jer bi na primjer nastavku -á u 3. licu jednine prezenta glagola odgovarala bifonematska skupina -iina, usp. čaká "čeka" prema vracia "vraća". Tu ne može biti riječi o umetanju infiksa, jer mu se ne bi mogao pridružiti morfološki plan sadržaja. Prema tome, u alomorfu bi dugi vokalski fonem alternirao s bifonematskom skupinom, a takve su alternacije u slovačkom iznimno rijetke (Král' - Sabol, 1989: 294; Sabol, 1989: 114).

Kao što se može primijetiti, bifonematsko poimanje slovačkih dvoglasnika otvara brojne fonološke nedoumice i proturječnosti, i upravo tu treba tražiti odgovor na pitanje zašto je bifonematska teorija u slovačkoj fonologiji danas potpuno napuštena.

Ako ne računamo Čeha Josefa Vacheka, ideju o monofonematskom karakteru slovačkih dvoglasnika prvi je iznio Ján Horecký (1974). Uz navedeni argument komutacijskih testova, Horecký (1974: 50) navodi rezultate spektrografske analize koja pokazuje da kliznici u dvoglasniku traju znatno kraće od kratkih samoglasnika. Sabol (1977: 22sq) dodaje da ni kod jednostavnih samoglasnika taj odnos nije $1: 2$, nego istraživanja pokazuju da iznosi između $1: 1,65$ (u prvom slogu riječi) do čak $1: 1,28$ (u petom slogu riječi). Ti podaci, prema Horeckom i Sabolu, slabe tezu o mornome shvaćanju kvantitete u slovačkom književnom jeziku, a kao posljedicu toga i bifonematsko vrednovanje slovačkih dvoglasnika (Horecký, 1974: 50; Sabol, 1989: 111). Međutim, sve je to zapravo prenošenje fonološke problematike na fonetsku razinu koja ne može biti presudno mjerilo.

Puno je jači fonetski argument koji se odnosi na realizaciju dvoglasnika. Istraživanja za Atlas slovačkih glasova pokazala su da se dvoglasnik može interpretirati “[...] kao jednostavni klizni zvuk, kao jedinstveni glas za koji je karakterističan određeni artikulacijski pokret i određena promjena sastava zvuka u vremenu", (Dvončová - Jenča - Král', 1969: 69).² Time je zadovoljeno i 2. pravilo Trubeckoga o razlikovanju samostalnoga fonema i skupine fonema. Prema tome pravilu skupine glasnika mogu se smatrati fonemom samo ako se tvore jedinstvenim artikulacijskim pokretom ili postupnim skraćivanjem, odnosno sužavanjem artikulacijskoga trakta (Trubeckoj, 1960: 64).

$\overline{2}$ „Ale foneticky možno dvojhlásky interpretovat’ aj inak. Nielen ako tesné a plynulé (kízavé) spojenie dvoch samohlások, pri ktorom sa oslabuje sonórnost' jedného člena, takže sa realizuje len jeden vrchol sonórnosti (slabičnosti), ale aj ako prostý kĺzavý zvuk, ako jedinú hlásku, pre ktorú je charakteristický daný artikulačný pohyb a daná zmena zvukovej skladby v čase.“ (Dvončová - Jenča - Král', 1969: 69) 
Sabol (1989: 114) navodi i sistemski kriterij: u teoriji distinktivnih obilježja duge samoglasničke foneme smatramo monofonematskima, jer svim postojećim obilježjima kratkoga samoglasnika dodajemo [+ duljina], a tada monofonematskima trebamo smatrati i dvoglasnike, budući da su dugim samoglasnicima funkcionalno ekvivalentni (u neutralizacijama i alternacijama). Horecký (1974:52) im dodaje inherentno obilježje [+ diftongičnost] koje se temelji na artikulacijskoj osobini klizavosti, a potrebno je da bi se razlikovali minimalni parovi rád "rado" riad "posuđe" ili nóta "diplomatska nota" nôta "napjev". No najsnažniji argument u korist monofonematskoga poimanja slovačkih dvoglasnika prema našem je mišljenju morfonološki kriterij. Naime, alomorfi slovačkih sufikasa i nastavaka najčešće imaju oblike koji se razlikuju u samoglasničkom dijelu, a u njima se smjenjuju dugi samoglasnik, dvoglasnik i kratki samoglasnik, na primjer:

$\begin{array}{lllll}\begin{array}{l}\text { novinár } \\ \text { "novinar" }\end{array} & - & \begin{array}{l}\text { fajčiar } \\ \text { "pušač" }\end{array} & - & \begin{array}{l}\text { mliekar } \\ \text { "mljekar" }\end{array} \\ \begin{array}{l}\text { prvák } \\ \text { "prvaš" }\end{array} & - & \begin{array}{l}\text { vlčiak } \\ \text { "vučjak" }\end{array} & - & \begin{array}{l}\text { vojak3 } \\ \text { "vojnik" }\end{array} \\ \begin{array}{l}\text { pekná } \\ \text { "lijepa" }\end{array} & - & \begin{array}{l}\text { cudzia } \\ \text { "strana" }\end{array} & - & \begin{array}{l}\text { múdra } \\ \text { "pametna" }\end{array} \\ \begin{array}{l}\text { chytám } \\ \text { "hvatam" }\end{array} & - & \begin{array}{l}\text { vešiam } \\ \text { "vješam" }\end{array} & - & \begin{array}{l}\text { čítam } \\ \text { "čitam" }\end{array}\end{array}$

Ekonomičnije je sve te sufikse i nastavke opisati kao pozicijski uvjetovane alomorfe koji se ostvaruju promjenom samoglasnika $\bar{a}-\underset{\wedge}{i} a-a$, pri čemu je raspodjela distinktivnih obilježja sljedeća:

$\begin{array}{ccc} & \text { duljina } & \text { diftongičnost } \\ / \overline{\mathrm{a}} / & + & - \\ / \mathrm{ia} / & + & + \\ \mathrm{h} / \mathrm{a} / & - & 0\end{array}$

Isto se događa pri kvantitativnim alternacijama koje nastaju pri tvorbi nekih morfoloških oblika poput genitiva množine imenica ženskoga i srednjega roda. Ako se taj lik tvori nastavkom $-\varnothing$, prethodni se slog produljuje. U skladu s načelom jednostavnosti i dalekosežnosti fonološkoga opisa, logično je da slučajeve poput hlava "glava" $\rightarrow$ hláv, zima $\rightarrow$ zím, mucha "muha" $\rightarrow$ múch opišemo jednako kao i slučajeve žaba $\rightarrow$ žiab, žena $\rightarrow$ žien, noha "noga" $\rightarrow$ nôh, tj. da se u svim tim slučajevima radi o istoj alternaciji. Prema tome,

3 U ovom se primjeru sufiks ne krati zbog djelovanja ritmičkoga zakona, nego zbog sinkronijskoga fonotaktičkog pravila po kojem se iza j ne mogu nalaziti dvoglasnici. 
duljenje $a \rightarrow$ ia jednako je kao i duljenje $a \rightarrow \bar{a}$, a tada dvoglasnik moramo smatrati monofonematskim elementom.

Argument koji govori u prilog monofonematičnosti slovačkih dvoglasnika možda je i činjenica da oni nisu položajno uvjetovani, poput na primjer slogotvornih sonanata 1, r r, 1 , $\bar{r}$. Nije dovoljno da se visoki samoglasnici $i, u$ pojave ispred nevisokih u potencijalno tautosilabičkom položaju da bi nastao dvoglasnik. Drugim riječima, slovački dobro razlikuje bifonematske skupine dvaju kratkih samoglasnika i dvoglasnike, iako se oni jednako bilježe u pismu, o čemu je već bilo riječi.

Problematika fonološkoga statusa /ie/ u hrvatskom jezikoslovlju mnogo je izraženija, budući da njegova fonematičnost još uvijek nije potpuno dokazana niti općeprihvaćena. Ono u čemu se svi autori slažu jest da je refleks dugoga praslavenskoga jata u hrvatskom jednosložan. Pritom ne uzimamo u obzir specifične slučajeve poput dvïje ili smïjēe (Brozović, 2006:60sq), kao ni poetska ostvarenja koja zahtijevaju dvosložan izgovor, a koja ne mogu biti presudno mjerilo fonološke interpretacije. Međutim, koplja se lome oko pitanja kakav je fonološki sastav toga jednoga sloga i o tome su se u znanosti o hrvatskom jeziku uspostavila dva temeljna gledišta.

Prema prvome, refleks dugoga jata u hrvatskom se jeziku ostvaruje kao jedinstveni dvoglasnik ie koji se u realizaciji razlikuje od dvosložnog slijeda ije, ali i od jednosložnoga slijeda jê. Glavni su pristaše takva shvaćanja Brozović (1991: 440) i Jelaska (2004: 76). Prema drugome shvaćanju, hrvatski refleks dugoga jata fonološki se može interpretirati kao /jē/, pri čemu se fonološki (i fonetski) ne razlikuje od istovjetnoga fonemskog slijeda koji nije refleks staroga jata, na primjer u riječi jêž. Zagovornici su te teorije, između ostalih, Škarić (1996) i Pranjković (1997/1998).

O tome je pitanju napisano mnogo radova, a rasprave su se naročito intenzivirale krajem devedesetih godina prošloga stoljeća, ponajprije u časopisu Jezik. Njihov iscrpan popis donosi Jelaska (2005). Budući da su argumenti obiju strana predstavljeni više puta i dobro su poznati akademskoj zajednici, na ovome ih mjestu nećemo u detaljima iznositi. Smatramo da je najveći nedostatak brojnih rasprava koje su napisani o toj temi preplitanje i zamjenjivanje fonetske, fonološke i pravopisne razine, pa se rasprava o izgovornom ostvaraju i fonološkoj interpretaciji dugoga jata na kraju često svede na kritiku grafijskoga rješenja (ije), koje je nesumnjivo loše, ali nije nužno povezano s fonološkom interpretacijom refleksa dugoga jata. Jedno je pitanje kako se u govoru ostvaruje refleks dugoga jata, drugo je fonološka interpretacija toga ostvaraja, a nešto posve treće pravopisna konvencija njegova grafičkoga bilježenja, koju ni u kojem slučaju ne bi trebalo olako mijenjati.

Svi ti brojni argumenti u korist jedne ili druge interpretacije zapravo se sudaraju na jednom i jedinom kritičnom pitanju: ostvaruje li se jednako refleks dugoga jata i takozvanoga produljenoga jata, na primjer u riječi vijeće prema vjeran? (Dokazivati distinkciju /ie/ /ije/ danas je potpuno bespredmetno, budući da o jednosložnome refleksu dugoga jata u hrvatskom jeziku vlada opći konsenzus). Zagovornici prve teorije smatraju da se u prvoj riječi fonetski i fonološki ostvaruje dvoglasnik ie koji se razlikuje od slijeda jē ostvarenoga u drugoj riječi. Zagovornici druge teorije smatraju da se u oba slučaja ostvaruje slijed jē te se zapravo ne radi o posebnom fonemu. 
U radu zastupamo stajalište da dug odraz jata nije poseban fonem, jedinstven dvoglasnik /ie/, nego se ostvaruje kao slijed/jē/, u najgorem slučaju može se tako fonološki interpretirati. Tomu u prilog ne govore samo spektrogramska analiza i slušni testovi (Škarić, 1996), nego i činjenica da za opoziciju ie jē ne postoji uvjerljiv minimalni par, a to ne može biti slučajnost. Primjer koji se obično navodi sijênā sjênā pomalo je nategnut, jer je sijeno inače singulare tantum, pa zapravo nema oblik genitiva množine, a par sijêna sjênā prije će se temeljiti na distinkciji $a-\bar{a}$ u padežnom nastavku, nego na različitom ostvaraju refleksa dugoga, odnosno produljenoga jata, kao i u poznatom paru dijêla djêlā. No, čak kada bismo i priznali taj primjer, ostaje otvorenim pitanje koliko bi govornika hrvatskoga doista registriralo različito značenje pri dvoglasnom ostvaraju, odnosno pri ostvaraju s dugim samoglasnikom.

Usporedimo li tu problematiku s onom slovačkih dvoglasnika, ustanovit ćemo da se načelno radi o istom problemu: o dvojbi između bifonematske (jē) i monofonematske (ie) koncepcije hrvatskoga dvoglasnika. Stoga će kao prilog rješenju te dvojbe biti korisno usporediti polazne postavke i rješenja u obim fonološkim tradicijama, budući da se radi o gotovo identičnoj dvojbi u strukturno sličnim sustavima:

1. Slovački samoglasnički sustav poznaje cijeli podsustav dvoglasnika koji su artikulacijski povezani - svi su uzlazni, a prvi im je dio neslogotvorni visoki samoglasnik. Štoviše, sistemsko funkcioniranje dvoglasnika otvara i nova mjesta u sustavu, poput marginalnoga "diftongoida" io. U hrvatskom je ie potpuno osamljen u samoglasničkom sustavu, a ne postoje slučajevi koji bi ukazivali na potencijalno otvaranje mjesta za druge dvoglasnike, što bismo očekivali u slučaju njegove utemeljenosti u fonološkom sustavu.

2. Fonološki je ekonomičnije opisati potencijalni fonem iz već postojećega fonološkog inventara, nego uvoditi novi fonem, ako su zadovoljeni drugi fonološki preduvjeti. Na primjer, /č/ bi bilo ekonomičnije opisati kao /tš/, međutim, tomu se protive drugi fonološki pokazatelji poput fonotaktičke distribucije: - $\check{c}$ se može pojaviti u finalnoj poziciji, ali ne i skupine $b \check{z}, p \check{s}, k \check{s}, g \check{z}$ i sl., koje su mu fonetski analogne. Interpretacija /č/ kao /ť̌s/ slama se ponajprije na slogovnoj podjeli: lik mača (genitiv jednine) slogovno se dijeli na $m a-\check{c} a$, a ne na $m a t-\check{s} a$, što u skladu s 1. pravilom Trubeckoga o razlikovanju fonema i skupine fonema (Trubeckoj, 1960: 63) upućuje na poseban fonem. Kod refleksa dugoga jata takve pokazatelje nemamo, pa je ekonomičnije refleks dugoga jata opisati kao /jē/, dakle jedinicama koje u sustavu postoje. U slovačkom jeziku dvoglasnike ne možemo tako lako opisati postojećim fonemskim inventarom. Kao što smo pokazali, pokušaji bifonematske interpretacije dvoglasnika propali su nakon što su naišli na teškoću fonološke identifikacije kliznika u prvom dijelu dvoglasnika, koji se inače pojavljuju kao alofoni sonanata $j$ i $v$, pa bi se slovački dvoglasnici sveli na bifonematske skupine ja, je... Hrvatskomu dugom jatu takvo što ne prijeti, jer se pri bifonematskom shvaćanju hrvatskoga dvoglasnika opozicija prema bifonematskoj skupini je ostvaruje distinkcijom /e/ /ê/.

3. Interpretacija refleksa dugoga jata pomoću /jē/ čini vokalski sustav logičnim i sustavnim, jer fonološki jedinstvenu alternaciju /je/ - /ie/ svodi na /e/ - /ē/, korelativnu s ostalim 
samoglasničkim alternacijama /a/ - /ā/, /i/ - /1/ itd. Sustavnija je, dakle, alternacija kratkoga samoglasnika s dugim, nego bifonematske skupine s dvoglasnikom. U slovačkom je problem obratan: budući da u slovačkom dvoglasnici alterniraju s kratkim samoglasnicima $(a-i a, \ddot{a}-i a, e-i e, o-\hat{o}){ }^{4}$ upravo monofonematsko poimanje slovačkih dvoglasnikā usustavljuje navedene alternacije $\mathrm{i}$ čini ih korelativnima s onima jednostavnih dugih samoglasnika $(a-a ́, i-i, u-u ́)$.

Možemo zaključiti da je problem fonološke interpretacije dvoglasnika u hrvatskom i slovačkom jeziku dijametralno suprotan, što proizlazi iz različitih samoglasničkih sustava i različitoga mjesta dvoglasnika u sustavima tih dvaju bliskih jezika.

Stječe se dojam da je posljednjih godina rasprava o refleksu dugoga jata u hrvatskom jezikoslovlju posustala, što je potpuno razumljivo s obzirom na to da su brojni višekratno izneseni argumenti više-manje iscrpljeni. Svrha je predstavljene studije iznijeti nov, koliko nam je poznato, dosad nespomenut kontrastivni argument koji će, nadamo se, udahnuti nov život u raspravu o refleksu dugoga jata, koju ni izdaleka ne možemo smatrati zaključenom.

$4 \quad$ Dvoglasnik iu u slovačkom jeziku ima vrlo ograničenu distribuciju i ne sudjeluje u alternacijama, što svjedoči o njegovu kasnijem, analoškom nastanku. 